\title{
HETEROGENEOUS CATALYSIS ON COMBUSTION SYNTHESISED $\mathrm{MgAl}_{2} \mathrm{O}_{4}$
}

\section{C.B.Talwatkar, R.H.Limsay, P.S.Deshpande, C Hatwar and R.S.Bhavsar*}

Department of Chemistry, Institute of Science, Nagpur-440001 (MS) INDIA

Corresponding author E-mail: dr.rajesh_bhavsar@rediffmail.com

\section{ABSTRACT:}

Magnesium aluminates, $\mathrm{MgAl}_{2} \mathrm{O}_{4}$, have been synthesized by solution combustion synthesis method using oxalyldihydrazide as a fuel and corresponding metal nitrates as oxidizer. It has been characterized by XRD, BET surface area and powder density measurements. Surface area has been measured by BET method and has a value of $12.67 \mathrm{~m}^{2} \mathrm{~g}^{-1}$. Particle size was calculated by using values of surface area and powder density, which has a value of $71 \mathrm{~nm}$. The $\mathrm{MgAl}_{2} \mathrm{O}_{4}$ powders thus synthesised have been used as a catalyst for the decomposition of $\mathrm{H}_{2} \mathrm{O}_{2}$ at two different temperatures. Activation energy has been found to be $299 \mathrm{Cal}^{\mathrm{mol}} \mathrm{H}^{-1}$ suggesting chemisorption is taking place.

Keywords: Solution combustion synthesis, $\mathrm{MgAl}_{2} \mathrm{O}_{4}$, Surface area, Catalyst.

\section{INTRODUCTION:}

Due to good chemical stability, high melting point and mechanical strength $\mathrm{MgAl}_{2} \mathrm{O}_{4}$ spinel is widely applied as ceramic materials. In recent years there has been growing interest in the utilization of $\mathrm{MgAl}_{2} \mathrm{O}_{4}$ spinel as a catalyst or catalyst support in different fields [1]. However, making high purity spinel from a powder obtained by solid state reaction route is difficult, since this technique needs repeated grinding and calcinations steps to get desired properties. Methods such as sol-gel, hydrothermal synthesis, plasma spray decomposition of oxides etc. could be used to produce high purity oxide powders but these methods require high purity expensive raw materials and many processing steps [2]. Recently solution combustion synthesis technique has emerged as an attractive method for the production high purity, homogeneous and crystalline oxide powders at very lower temperature requiring very short time periods using less amount of energy as well. 
In present work we have used solution combustion synthesized $\mathrm{MgAl}_{2} \mathrm{O}_{4}$ spinel for decomposition of hydrogen peroxide in heterogeneous catalysis.

\section{EXPERIMENTAL:}

The starting chemicals used in this study were aluminium nitrate (Merck), magnesium nitrate (Merck), diethyl oxalate (Merck), hydrazine hydrate (Loba) and hydrogen peroxide (Merck). The stoichiometry of the metal nitrates and fuels was calculated based on total oxidizing and reducing valency of the oxidizer and fuels, which serve as numerical coefficient for stoichiometric balance so that the equivalence ratio, $\Phi_{\mathrm{e}}$ is unity [3]. In this method metal nitrates acts as oxidizer and oxalyldihydrazide as a fuel. The fuel, oxalyldihydrazide was prepared by dropwise addition of one mole of diethyl oxalate to two moles of hydrazine hydrate (99-100\%) at room temperature as reported in [4]. A white precipitate was formed which was washed, filtered and dried over $\mathrm{P}_{2} \mathrm{O}_{5}$ in a vacuum. The amount of oxidizers and fuels were taken in such a way that the desired product i.e. $\mathrm{MgAl}_{2} \mathrm{O}_{4}$ formed is $5 \mathrm{~g}$. The mixture was dissolved in minimum quantity of water in a $250 \mathrm{ml}$ capacity Borosil make glass beaker. The beaker containing mixture was introduced into a muffle furnace maintained at $773 \mathrm{~K}$. The mixture boils, froths, foams and produce large quantities of gases yielding voluminous and foamy $\mathrm{MgAl}_{2} \mathrm{O}_{4}$. The theoretical equation for the formation of $\mathrm{MgAl}_{2} \mathrm{O}_{4}$ can be written as follows:

$\mathrm{Mg}\left(\mathrm{NO}_{3}\right)_{2 \text { (aqua) }}+2 \mathrm{Al}\left(\mathrm{NO}_{3}\right)_{3}$ (aqua) $+4 \mathrm{C}_{2} \mathrm{H}_{6} \mathrm{~N}_{4} \mathrm{O}_{2}$ (aqua) $\rightarrow \mathrm{MgAl}_{2} \mathrm{O}_{4}$ (s) $+12 \mathrm{~N}_{2}$ (g) $\uparrow+8 \mathrm{CO}_{2} \uparrow$ $+12 \mathrm{H}_{2} \mathrm{O}_{(\mathrm{g})} \uparrow$

The crystallinity and phase identification of the powders were determined by using Philips PW-1700 X-ray diffractometer with Ni filtered Cu Ka radiations. Surface area measurement was done using nitrogen gas adsorption multipoint Brunquer-Emmett-Teller (BET) method using Micromeritics ASAP 2010 model, assuming a cross-sectional area of $0.162 \mathrm{~nm}^{2}$ for nitrogen molecule. Powder density was measured using a pycnometer with xylene as the liquid medium. 
The diameter of the primary particle was calculated from the superficial area using following equation:

$$
\mathrm{D}_{\mathrm{BET}}=6 / \mathrm{S}_{\mathrm{BET}}{ }^{*} \rho
$$

Where, $\mathrm{S}_{\mathrm{BET}}$ Is the superficial area $\left(\mathrm{m}^{2} \mathrm{~g}^{-1}\right)$ measured by BET analyses, $\rho$ is the density of powder $\left(\mathrm{g} \mathrm{cm}^{-3}\right)$ and $\mathrm{D}_{\mathrm{BET}}$ is the diameter of the produced particle.

The magnesium aluminate thus synthesized used as such without any modification as a catalyst for the decomposition of hydrogen peroxide. $5 \mathrm{~cm}^{3}$ very dilute $\mathrm{H}_{2} \mathrm{O}_{2}$ solution (solution of $\mathrm{H}_{2} \mathrm{O}_{2}$ was prepared in such a way that after decomposition the total gas evolved is $50 \mathrm{~cm}^{3}$ ) was taken in a $100 \mathrm{~cm}^{3}$ capacity reaction vessel. To it $100 \mathrm{mg}$ catalyst powder was added. The reaction vessel was connected to gas burette. Water reservoir of the gas burette was adjusted at 0 $\mathrm{cm}^{3}$. Then the pressure in the gas burette was adjusted to 1 atmosphere (by making the water level in gas burette and reservoir to stand at the same level). The contents in the reaction vessel were constantly stirred and volume of the gas evolved was recorded. Volume of the gas evolved was recorded at the intervals of 5 minutes, $\left(\mathrm{V}_{\mathrm{t}}\right)$, adjusting each time the pressure in the gas burette to atmospheric one. Without disconnecting the reaction vessel from the gas burette the contents were heated in a boiling water bath so as to complete the decomposition of $\mathrm{H}_{2} \mathrm{O}_{2}$. When the gas ceases to evolve, the reaction vessel was cooled to the temperature of the experiment i.e. $308 \mathrm{~K}$ and final volume $\mathrm{V}_{\infty}$ was recorded. In order to determine the energy of activation the experiment was repeated at another temperature i.e, at $318 \mathrm{~K}$. The initial concentration at any time ' $\mathrm{t}$ ' is proportional to $\left(\mathrm{V}_{\infty}-\mathrm{V}_{\mathrm{t}}\right)$. A plot of $\log \left(\mathrm{V}_{\infty}-\mathrm{V}_{\mathrm{t}}\right)$ against time ' $\mathrm{t}$ ' was plotted, the slope of which give us the value, - $\mathrm{K} / 2.303$. The rate constant ' $\mathrm{K}$ ' was calculated using following relation:

$$
\mathrm{K}=2.303 / \mathrm{t} * \log \mathrm{V}_{\infty} /\left(\mathrm{V}_{\infty}-\mathrm{V}_{\mathrm{t}}\right)
$$

The energy of activation ' $\mathrm{E}$ ' $\left(\mathrm{Cal} . \mathrm{mole}^{-1}\right)$ was obtained from the following relation: 


$$
\log \mathrm{K}_{2} / \mathrm{K}_{1}=-\mathrm{E} / 2.303 \mathrm{R} *\left[1 / \mathrm{T}_{2}-1 / \mathrm{T}_{1}\right]
$$

Where, $\mathrm{E}$ is the energy of activation. $\mathrm{K}_{1}$ and $\mathrm{K}_{2}$ are specific rate constants at two temperatures $\mathrm{T}_{1}$ and $\mathrm{T}_{2}$. $\mathrm{R}$ is gas constant.

\section{RESULTS AND DISCUSSION:}

The solution combustion synthesis using oxalyldihydrazide as a fuel was found to be successful in producing crystalline, phase pure powders of $\mathrm{MgAl}_{2} \mathrm{O}_{4}$ at a temperature less than $773 \mathrm{~K}$ within ten minutes time. Generally, suitable fuels react non-violently, produce non-toxic gases and acts as good complexant for metal cations [5-6].

The XRD pattern of as synthesized $\mathrm{MgAl}_{2} \mathrm{O}_{4}$ is shown in Fig.1. It is observed that only a single phase has been formed and oxide is crystalline in nature. The powder XRD shows very sharp peaks, which can be attributed to high exothermicity of solution combustion process.

BET surface area was found to be $12.67 \mathrm{~m}^{2} \mathrm{~g}^{-1}$. Powder density was calculated by pycnometer using xylene as liquid medium. The value of the same was found to be $6.68 \mathrm{~g} \mathrm{~cm}^{-3}$. The average particle diameter obtained by specific surface area measurement and density values was found to be $71 \mathrm{~nm}$.

From the characterization of $\mathrm{MgAl}_{2} \mathrm{O}_{4}$ it is observed that the material is stable having moderate surface area. It was thought to use this material as a catalyst. The decomposition of hydrogen peroxide $\left(\mathrm{H}_{2} \mathrm{O}_{2}\right)$ was studied using $\mathrm{MgAl}_{2} \mathrm{O}_{4}$ as a catalyst.

$$
2 \mathrm{H}_{2} \mathrm{O}_{2}(1) \stackrel{\mathrm{MgAl}_{2} \mathrm{O}_{4}}{\longrightarrow} \text { (s) } 2 \mathrm{H}_{2} \mathrm{O}+\mathrm{O}_{2}
$$

This is an example of heterogeneous catalysis involving liquid reactants while catalyst is present in the solid form. The decomposition of $\mathrm{H}_{2} \mathrm{O}_{2}$ was studied at two different temperatures, $308 \mathrm{~K}$ and $318 \mathrm{~K}$ at time ranging from 0 to 30 minutes in the intervals of 5 minutes. The results obtained are presented in 
Fig. 2 as a plot of $\log \left(\mathrm{V}_{\infty}-\mathrm{V}_{\mathrm{t}}\right)$ versus time' $\mathrm{t}$ '. The value of activation energy was found to be 299 Cals.mole $^{-1}$. High value of activation energy suggests that chemisorption is taking place with monolayer formation [7]. The catalytic activity of the catalyst may be due to the presence of free valencies on its surface. These free valencies offer an opportunity to the reactant molecule to undergo chemical reaction on the surface of catalyst. With the decrease in size of the catalyst, the free surface area is increased, whereby free valencies or active spots increases, which are responsible for the adsorption of reactant molecule [8].

\section{CONCLUSION:}

Solution combustion synthesis has produced a crystalline, phase pure, moderate surface area powders of $\mathrm{MgAl}_{2} \mathrm{O}_{4}$ at a temperature less than $773 \mathrm{~K}$ within ten minutes of time, which shows the energy efficiency, and time saving nature of the method. The magnesium aluminate produced has been successfully used as a catalyst in heterogeneous catalysis. Wherein chemisorption is taking place with monolayer formation.

\section{REFERENCES:}

Salmones J, Galica J A, Wang J A, Valenzuela M A and Aguilar-Rios, Journal of Material Science Letters, 19 (2000) 1033.

Ganesh I, Jhonson R, Rao G V N, Mahajan Y R, Mahadevendra S S, Reddy B M, Ceramic International, 31 (2005) 67.

Jain S R, Adiga K C, Paivernekar V R, Combst. Flame, 40 (1987) 71.

Gran G, Anal. Chem. Acta. ,14 (1956) 150.

Lima M D, Bonadimann R, de Andarade M J, Toniolo J C, Bergmann C P, J.Euro.Cer.Soc., 26 (2006) 1213-1220. 
Abecassis-Wolfovich M, Rotter H, Landau M V, Korin E, Ernburg A I, Mogilyansky D et al., J. Non-Cryst. Solids, 318 (1/2) (2003) 95.

Bond G C, Heterogeneous Catalysis Principals and Applications, 2nd edition, (Oxford Science Pubication) 1987.

Chhatwal G R, Mehra H, Advanced Physical Chemistry (Goel Publishing House, Meerut) 1985. 
International Journal of Researches in Biosciences, Agriculture \& Technology
September 2013

Issue-1, Volume-1
ISSN No. (Online): 2347-517X

\section{Counts $\rightarrow$}

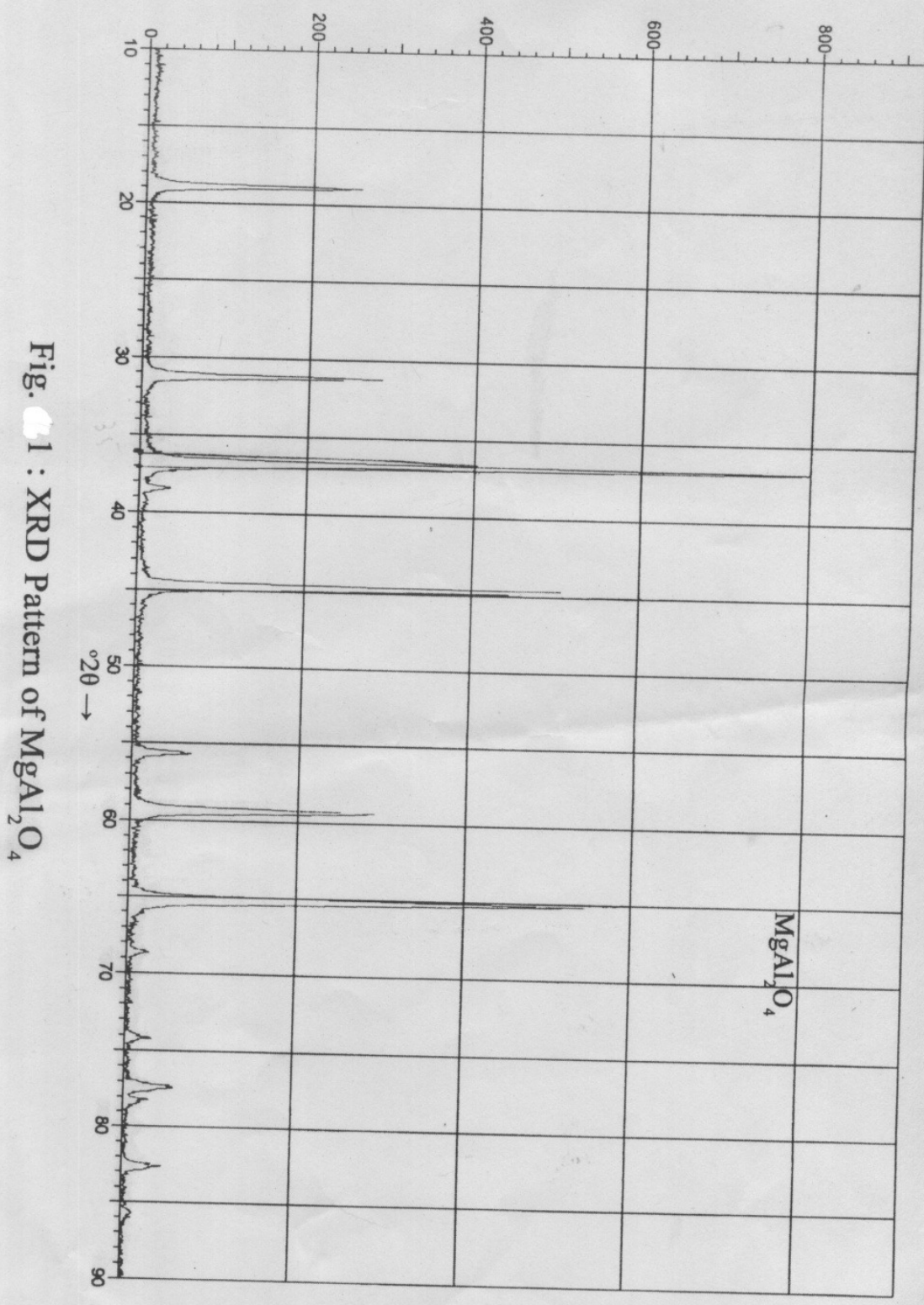


International Journal of Researches in

September 2013

ISSN No. (Online): Biosciences, Agriculture \& Technology

Issue-1, Volume-1
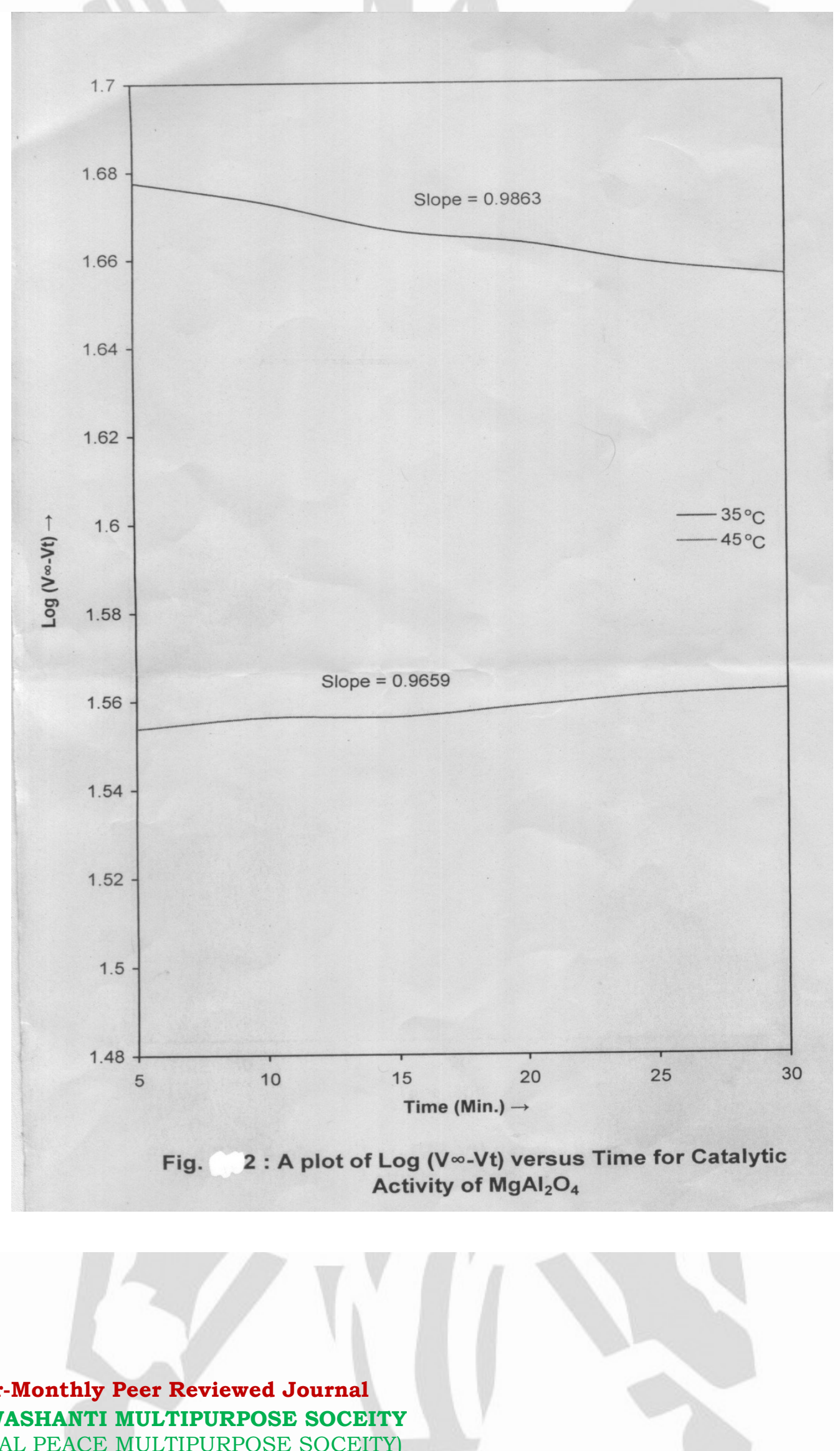